\title{
REPENSANDO OS CÂNONES DO PENSAMENTO SOCIAL BRASILEIRO: AS TESES DE 1905, DE MANOEL BOMFIM
}

\author{
José Geraldo dos Santos' \\ Patrick Silva dos Santos ${ }^{2}$
}

RESUMO: Este artigo tem por objetivo apresentar as teses de Manoel Bomfim (1868-1932) em "A América Latina: males de origem" (1905), livro escrito no período em que ele se doutorava na França. Com isso, pretendemos demonstrar a importância de suas teses, no que concerne uma forma de interpretar o Brasil, que o aproxima das produções posteriores dos cânones pertencentes à chamada geração de 30. Assim, a reflexão do médico sergipano em relação ao problema brasileiro e latino-americano contribuiu decisivamente na formação do sistema de temas das Ciências Humanas e Sociais brasileiras, que posteriormente seriam mobilizados por outros autores em diferentes contextos e com certas similaridades, mas também diferenças. Em síntese, tais contribuições de M. Bomfim são os elementos que nos orientam na adoção de uma perspectiva de repensar os cânones do Pensamento Social Brasileiro.

PALAVRAS-CHAVE: Manoel Bomfim; cânones; interpretação do Brasil; formação social; Pensamento social brasileiro.

\section{RETHINKING THE CANOS OF BRAZILIAN SOCIAL THOUGHT: THE TESES OF 1905 BY MANOEL BOMFIM}

Pelo Programa de Pósgraduação em História $(\mathrm{PPGH})$, da Universidade Salgado de Oliveira (UNIVERSO); Mestre em História pela mesma instituição.

\footnotetext{
2 Doutorando em Sociologia. Pelo Programa de Pósgraduação em Sociologia (PPGS), da Universidade Federal Fluminense (UFF); Mestre em Sociologia. Pelo mesmo programa e instituição; Graduado em Ciências Sociais.
}

ABSTRACT: This article aims to present Manoel Bomfim's theses (18681932) in "A América Latina: males de origem" (1905), a book written during the period when he was doing his doctorate in France. With this, we intend to demonstrate the importance of his theses, in what concerns, a way of interpreting Brazil that brings him closer to the later productions of the canons belonging to the so-called generation of 30. Thus, the reflection of the Sergipe doctor in relation to the Brazilian problem and Latin American contributed decisively to the formation of the Brazilian Human and Social Sciences themes system, which would later be mobilized by other authors in different contexts and with certain similarities, but also differences. In summary, such contributions by M. Bomfim are the elements that guide us in adopting a perspective to rethink the canons of Brazilian Social Thought.

KEYWORDS: Manoel Bomfim; canons; interpretation of Brazil; social formation; Brazilian Social Thought. 


\section{INTRODUÇÃOO}

Manoel José do Bomfim nasceu no ano de 1868, na província de Aracaju, em Sergipe. Era filho de Maria Joaquina do Bomfim e de Paulino José do Bomfim, um respeitado comerciante e dono de engenho de Aracaju, que havia sido vaqueiro durante a infância. Em 1891, Manoel Bomfim casou-se com a jovem portuguesa Natividade Aurora de Oliveira e com ela Bomfim teve dois filhos: Maria, que veio a falecer em 1894, com um ano e dez meses de idade, vitimada por uma epidemia de tifo, e em agosto do mesmo ano nasceu seu filho Aníbal (AGUIAR, 2000; GONTIJO, 2010).

Bomfim fez seus estudos em Medicina em duas prestigiadas instituições de ensino brasileiras: em 1886 ingressou na Faculdade de Medicina da Bahia e dois anos mais tarde transferiu-se para a Faculdade de Medicina do Rio de Janeiro, formando-se em 1890. No ano de 1902, quando foi montada uma comissão pedagógica nomeada pela prefeitura, e fazendo parte dessa comissão, Manoel Bomfim foi para Paris, onde se doutorou em Psicologia sobre a orientação de Alfred Binet, na Sorbonne (AGUIAR, 2000; GONTIJO, 2010; GIL, 2016). $\mathrm{Na}$ condição de estudante neste momento na Sorbonne, teve como mestres importantes nomes da psicologia francesa do período, os discípulos de Théodule-Armand Ribot: Henri-Étienne Beaunis, Pierre Janet, Charles Henry, Toulouse, Dumas etc. (MEDEIROS, 1935).

Todavia, Manoel Bomfim se notabilizou por sua atuação no campo educacional da Primeira República, tendo ocupado diversos cargos de importância nesta área. Em 1896, foi nomeado pelo prefeito Francisco Furquim Werneck de Almeida (1846-1908), o novo subdiretor do Pedagogium ${ }^{3}$, tendo sido efetivado como diretor geral dessa instituição em 1897; no mesmo ano, passou a lecionar na Escola Normal da República na cadeira de moral e cívica e, no ano seguinte, 1898, tornou-se diretor interino da Escola Normal. Também foi nomeado diretor de Instrução Pública do Distrito Federal, tendo exercido esta função em outras oportunidades; lecionou na cadeira de Pedagogia e Psicologia Aplicada (ambas as disciplinas ministradas por ele na Escola Normal); em 1904, participou da criação da Upel Universidade Popular de Ensino Livre, juntamente com Elysio de Carvalho, Rocha Pombo, Fábio Luz, José Veríssimo, entre outros, sendo
${ }^{3}$ Fundado no ano de 1890, por meio do decreto 667 , de 16/08/1890, lavrado por Benjamin Constant, o Pedagogium foi uma instituição educacional, que inicialmente funcionou na Rua Visconde do Rio Branco, 13, no centro da cidade do Rio de Janeiro RJ. No ano de 1897 foi transferido para a Rua do Passeio, 66, também no centro da cidade, onde funcionou até seu fechamento, em 1919. Joaquim José de Menezes Vieira (1890 a 1897) e Manoel Bomfim, entre os anos de 1897 a 1906 e de 1910 até 1919 foram diretores desta Instituição. 
essa instituição de ensino superior de tendências anarquistas. Em 1906, inaugura no Pedagogium o primeiro laboratório de psicologia experimental do Brasil (MEDEIROS, 1935; ANTUNES, 1998), e em 1907, ele assume a vaga aberta na Câmara dos Deputados pelo Estado de Sergipe. No ano seguinte, buscou a reeleição e não obteve êxito (AGUIAR, 2000; GONTIJO, 2010).

Manoel Bomfim publica em 1905 "A América Latina: males de origem" ${ }^{4}$ pela editora francesa $H$. Garnier. $O$ livro é fruto direto da visão estereotipada dos europeus em relação às populações latinoamericanas - e também pela aceitação destes "estigmas" por parte da intelectualidade brasileira e sul-americana formulada por meio da aceitação parcial e/ou adaptação das Teorias deterministas raciais e geográficas (SCHWARCZ, 1993). Os usos científicos por parte significativa de seus contemporâneos foram os elementos explicativos importantes em seu primeiro livro do gênero, ao esclarecer os interesses de parte da intelectualidade ao tomarem os determinismos como mecanismos primordiais para a explicação do atraso brasileiro. Portanto, Bomfim enxergou a tentativa de uma dupla dominação: a) no plano interno - das elites econômicas e intelectuais para com grande fração da população nacional e b) no plano externo - das nações centrais para com as nações periféricas (ALVES FILHO, 1979).

Após todo o exposto, sustentaremos aqui de forma propositiva a ampliação dos cânones do Pensamento Social por entendermos que "A América Latina: males de origem" abriu caminho para outra forma de ler o Brasil, para além dos "receituários" importados da ciência europeia que a priori nos condenavam e mantinham-nos à margem da "civilização". Contudo, no plano metodológico, a ampliação do cânone não se circunscreve meramente numa mera adoção da noção de antecipação de postulados, mesmo porque aqui reconhecemos os limites, as singularidades e as diferenças contextuais de produção de determinados pressupostos posteriormente reformulados pelo ensaísmo sociológico atribuído à geração de 30. Nesse sentido, nos guiamos por meio da noção de sequências cognitivas (BOTELHO, 2007; 2019) por reconhecer que no âmbito das ciências humanas e sociais brasileiras formou-se um sistema de problemas e contradições, e que, em alguma medida, cada um dos textos aqui analisados

\footnotetext{
${ }^{4}$ Segundo o sociólogo Antonio Candido e o antropólogo Darcy Ribeiro, Manoel Bomfim em $A$ América Latina: males de origem abordou de forma inovadora e com grande profundidade temas centrais, antes trabalhados de forma insatisfatória, possibilitando compreender a formação social brasileira, os problemas nacionais, as desigualdades raciais justificadas por toda a sorte de perspectivas "cientificas" deterministas. Ou seja, de maneira inovadora para o período foram formuladas as narrativas-textuais de Bomfim em seu ensaio histórico-sociológico de 1905.
} 
comparativamente possuem autonomia e validade independentes uns dos outros, ou seja, "formam um conjunto analítico e que, assim considerados, expressam conquistas cognitivas heurísticas cruciais da sociologia" (BOTELHO, 2007, p.76). Em outras palavras, a noção de sequências cognitivas parece-nos um importante guia, uma vez que os desafios de qualquer sociedade estão de alguma forma associados ao seu desenvolvimento histórico do passado (BENDIX, 1996), o que, por conseguinte, garantiria certa convergência temática nos trabalhos desses autores (BOTELHO, 2007; 2019).

\section{PONTOS-CHAVE DE FUNDAÇÃO DISCURSIVO-TEXTUAIS EM "A AMÉRICA LATINA: MALES DE ORIGEM" (1905)}

Manoel Bomfim, por meio do seu conceito de Parasitismo Social, metáfora biológica cujo sentido buscava elucidar a dominação sociopolítica em meio à dualidade endógena e exógena, ele explicou estruturalmente a dupla dominação: por um lado, no plano interno das elites econômicas e intelectuais para com grande fração da população nacional - e, por outro lado, no plano externo - das nações centrais para com as nações periféricas. Assim, Bomfim entendeu as concepções científicas tomadas por parte considerável dos seus contemporâneos como uma falsa ciência, pois, para além de servirem como instrumentos de dominação entre os segmentos populacionais, não se atestava a veracidade de determinados pressupostos.

Nesse sentido, podemos compreender uma dimensão central motivacional e reflexiva de seu ensaio: tornar legível o que a voga científica do período escondia. As reflexões centrais e as anotações avulsas começam a ser feitas por Manoel Bomfim dez anos antes de sua publicação, isto é, em 1897, quando ele era membro do Conselho Superior de Instrução Pública (BOMFIM, 1905). Nesta condição, fez um parecer do livro didático "História da América" (1897) de Rocha Pombo. Nesse momento, já existia um "embrião" do livro de Bomfim e sua estadia na Europa, mais precisamente na França, só veio a impulsionar a materialização em forma de livro de suas reflexões e anotações que já vinham sendo feitas. Como explica o próprio Manoel Bomfim no prefácio de "A América Latina", cujo autor intitulou "Advertência", escrito em março de 1903, na cidade de Paris: 
Este livro deriva directamente do amor de um brasileiro pelo Brasil, da solicitude de um americano pela America. Começou no momento indeterminado em que nasceram esses sentimentos; exprime um pouco o desejo de vêr esta patria feliz, prospera, adiantada e livre. Fôram estes sentimentos que me arrastaram o espirito para reflectir sobre essas cousas, e o fizeram trabalhar essas ideias - o desejo vivo de conhecer os motivos dos males de que nos queixamos todos. (...) Estas mesmas, agora desenvolvidas, já as apresentei, em parte, resumidamente num parecer, prefacio á excellente Historia da America, livro didactico do Sr. Rocha Pombo, parecer que deriva justamente dessa preoccupação, já antiga. Em 1897, quando o Director Geral de Instrucção Publica fez annunciar o concurso de um compendio de Historia da America, sollicitei a honra de, na qualidade de membro do Conselho Superior de Instrucção Publica, dar o parecer sobre as obras que se apresentassem: tal era o interesse que este assumpto apresentava para mim; e só assim se explica essa pretensão de tratar de materia fóra da minha especialidade, e á qual não podia apresentar nenhum titulo de competencia official. (...) As notas se amontôam, o livro se forma a pouco e pouco - observações e reflexões, colhidas em cada uma das crises, desalentos, duvidas e enthusiasmos da vida que, entre difficuldades, vamos vivendo. Chegando aqui, á Europa, não só a natural saudade daquelles céos americanos, como a apreciação directa dessa reputação perversamente malevola de que é victima a America do Sul, provocaram a reacção affectiva que se traduz na publicação destas paginas. Fóra dahi, ellas não viriam, talvez, á luz. (BOMFIM, 1905, p.IX,X,XI [grifos do autor])

A importância de "A América Latina: males de origem" foi grande para o sucesso e prestígio de Manoel Bomfim durante a Primeira República. Tanto que o título do seu livro era citado nos jornais da época como uma espécie de adjetivo que acompanhava a apresentação do autor (SANTOS, 2017b). Ainda que o livro tenha representado o primeiro grande trabalho de Bomfim fora de sua especialidade, o seu conteúdo, gerou a revolta dos homens de "sciencia", que seguiam os dogmas deterministas produzidos no continente europeu (SCHWARCZ, 1993). Não à toa que o livro de Bomfim esteve situado em uma intensa discussão com os intelectuais: Nina Rodrigues, Euclides da Cunha, João Batista de Lacerda e Sylvio Romero (OLIVEIRA, 2015). Um bom exemplo, a ser aqui rapidamente 
lembrado, diz respeito a todo um ataque feroz feito ao livro de Manoel Bomfim pelo seu conterrâneo, o também sergipano, Sylvio Romero.

Em 1906, Sylvio Romero inicia o ataque às teses de Manoel Bomfim, saindo em defesa dos "homens de sciencia" do continente europeu, publicando neste ano uma série de artigos na revista "Os Anais" com o título "Uma suposta teoria nova da história latinoamericana", tendo Romero por objetivo central a desqualificação do médico, Manoel Bomfim e seu livro "A América Latina: males de origem". O conjunto dos artigos vieram a ser posteriormente reunidos e publicados em formato de livro pela livraria portuguesa Chardron, da cidade do Porto, intitulado "A América Latina: análise do livro de igual título do Dr. M. Bomfim". Em seu ataque, Sylvio Romero (1906) o fazia motivado pela sua defesa militante aos teóricos europeus que justificavam o atraso brasileiro e latino-americano por meio das mais variadas teorias deterministas raciais. Dentre os livros homônimos, a história os "julgara", em certa medida, dando o devido valor aos conteúdos diametralmente distintos redigidos em suas páginas ${ }^{5}$.

Em 1905, Manoel Bomfim usou de forma coerente e substancial o pressuposto analítico de se tomar o passado colonial como elemento explicativo fundamental da realidade social vivenciada nas sociedades sul americanas ${ }^{6}$. Ou seja, só por meio da análise desse desenvolvimento histórico seria possível apreender a continuidade da colonização refletida no domínio das elites oligárquicas. Neste sentido, em seu livro os processos históricos têm função central na compreensão dos "males de origem", que se desenvolveram desde as dinâmicas sociais entre os distintos segmentos populacionais, até mesmo na distorcida democracia liberal burguesa, cujas instituições sociais e burocracias estatais conservavam os vícios e distinções da ordem estamental de outrora ${ }^{7}$ (FERNANDES, 2017).

O desmonte das teses deterministas climáticas e raciais foi outro ponto importante trabalhado por Manoel Bomfim em seu ensaio. No entanto, ao invés de detalhar uma a uma e, daí por diante, elencar seus problemas, o autor não se preocupou com o funcionamento interno de cada uma dessas teorias. Assim, por meio da terminologia "Teoria do valor das Raças", fez uma espécie de generalização para todas as teorias que tinham uma mesma linha explicativa das capacidades
${ }^{5}$ Ao analisar a polêmica entre Sylvio Romero e Manoel Bomfim tomando por meio analítico a circulação dos livros homônimos, o sociólogo, Antonio Candido (2004) afirmou que mesmo com toda a erudição de Sylvio Romero e o cuidado com que produziu o livro resposta ao ensaio histórico-sociológico de Manoel Bomfim. Ainda assim, o livro de Romero caiu no esquecimento - já, por outro lado, não se poderia dizer o mesmo sobre $A$ América Latina: males de origem de Bomfim, que ao longo dos anos tiveram outras edições, e, por conseguinte vem sendo lido e estudado por diversas gerações de pesquisadores, pesquisadoras e intelectuais brasileiros, tanto dentro, quanto fora do Brasil.

6 Segundo Antonio Candido (1990) a originalidade de Manoel Bomfim em $A$ América Latina: males de origem fora lidar com problemas antes refletidos de maneira insatisfatória com maior robustez e lucidez que seus contemporâneos, por exemplo: o imperialismo norte-americano em ascensão; os determinismos raciais; o conservadorismo das elites brasileiras e por extensão latino-americana e o peso do passado colonial continuamente estruturandose nas relações espoliativas e assimétricas destas jovens repúblicas.

${ }^{7} \mathrm{Na}$ perspectiva de Manoel Bomfim, o Conservadorismo Essencial é uma questão central em A América Latina. males de origem, pois é um elemento do caráter latinoamericano, adquirido por meio da herança e educação transmitidas a nós por meio da relação mantida por séculos com os povos colonizadores do continente. 
raciais como elemento determinante, hereditário e imutável para o desenvolvimento das nacionalidades. Em outras palavras, não era como se repetia essa sentença que preocupou Bomfim, mas sim o que tais explicações buscavam legitimar.

Não obstante, sustentaram Roberto Ventura e Flora Sussekind (1984) que Bomfim por meio de sua teoria biológica da mais-valia demonstrou como as dinâmicas sociais coloniais se tornaram de fato nossos males nas mais variadas dimensões, sendo somente substituído o parasita do passado (o colonizador), por novos parasitas. Isto é, na metáfora bomfimniana, em última análise, o parasita se alterou, mas os parasitados continuam sendo os mesmos.

Destarte, dentro da área das Ciências Humanas e Sociais brasileira convencionou-se tratar as interpretações sobre o Brasil da chamada geração de 30 como uma espécie de fundação interpretativa destoante de toda uma tradição intelectual anterior, tendo como figuras centrais desta arquitetura "inovadora" nomes como Gilberto Freyre, Sergio Buarque de Holanda e Caio Prado Jr., por exemplo. No entanto, nos parece equivocada esta construção por sua generalização. Isto é, se tal pressuposto fosse em relação à fração majoritária dos intelectuais anteriores faria sentido, mas ao se colocar como universalista desconsidera o outro lado, ou seja, o lado oposto desta tradição intelectual anterior. Neste sentido, nos parece falsa esta suposta dicotomia entre o que se produzia antes e depois da geração de 30. Demonstraremos no prosseguir do texto que há mais similitudes do que antagonismos entre Bomfim e seus sucessores da geração de 30 .

\section{AS TESES DE MANOEL BOMFIM E AS SEQUÊNCIAS COGNITIVAS NA GERAÇÃO DE 30}

Em "A América Latina: males de origem" (1905), o continuísmo com os signos do passado colonial é um elemento central em toda sua análise, constitui-se o aspecto balizador de toda a sua narrativa-textual. Logo, podemos notar que o que mais tarde seria a centralidade analítica de nossa geração de 30, já o era em 1905 para Bomfim. Na terceira parte do livro, intitulada "As Nações colonizadoras da América do Sul", o médico sergipano buscou pistas no passado das nações da 
península ibérica para diagnosticar os males das jovens repúblicas egressas do sistema de exploração colonial. Como o próprio Manoel Bomfim aponta em seu trabalho, suas preocupações residem sobretudo no ramo da Psicologia Social, até por isso a imersão no passado ibérico seria um meio de compreender os efeitos da exploração colonial impetrada aqui por espanhóis e portugueses na conformação do mind set compartilhado por certa fração dessas populações.

No processo de educação colonizadora ibérica, dimensões importantes para a compreensão dos entraves para o progresso social seriam, para Bomfim,: em primeiro lugar, a vontade dos grupos aristocráticos em conservar as sociedades inertes, no mesmo estado de coisas, marcado por um sistemático conservadorismo que garantiria, em última análise, a manutenção de certos privilégios; em segundo lugar, teria se consolidado, por meio desse modus operandi, uma naturalização do viver a partir da exploração de terceiros, criando assim uma ética e moral afastadas das atividades laborais. Portanto, sustentava Manoel Bomfim que as nações ibéricas, já viciadas no viver parasitariamente, educaram as novas sociedades por meio da reprodução social sistemática deste "processo civilizador" (ELIAS, 1994), por isso, a

(...) sociedade colonial comprehendia, então, duas classes, perfeitamente distinctas - os escravos indios e pretos, e as varias sortes de instrumentos que a metropole atirava para lá, afim de apropriar-se do trabalho desses escravos. Só depois é que, entre uma e outra dessas duas classes, se foi formando uma terceira, que se apresentará então como o novo elemento americano. Os unicos que poderiam reclamar, si soubessem, se tivessem o direito de fallar, esses coitados! A colonia é parasitada; mas, mesmo dentro da colonia, o parasitismo se exerce. - Em summa, a victima das victimas é o escravo, e este é o unico que não tem voz, nem para queixar-se. (BOMFIM, 1905, p. 113)

Porquanto, Manoel Bomfim destaca no caso brasileiro a expertise do colonizador português em estabelecer laços de sangue como estratégia para povoar e colonizar um território tão grande. Pois, sem tal estratégia, uma nação com uma população ínfima não conseguiria estabelecer seus domínios em um vasto território. Sem 
contar, como o autor sugeriu, que se tratavam de povos já acostumados com séculos de misturas raciais dentro do próprio continente europeu (BOMFIM, 1905; SANTOS, 2017a).

Antes mesmo da observação em relação à moral aqui construída descrita por Sergio Buarque de Holanda e até mesmo as relações econômicas coloniais intimamente ligadas à degradação do trabalho livre descritas por Caio Prado Junior, mais de três décadas antes Manoel Bomfim descreveu que a adaptação do parasitado às condições que the foram impostas refletiu seriamente sobre o desenvolvimento pregresso das relações econômicas. Segundo o autor, a forma em que se desenvolveu o trabalho aqui possui intimas ligações com o regime de trabalho compulsório e as demais relações envolvidas neste processo, pois a escravidão "foi a abjecção moral, a degradação do trabalho, o embrutecimento e o aniquilamento do trabalhador; e foi tambem a viciação da producção, gerando males de effeitos extensissimos" (BOMFIM, 1905, p. 132). Assim, em Manoel Bomfim o processo de produção colonialista gerou consequências traumáticas para o desenvolvimento saudável dos países latino-americanos. Isso porque, nas

(...) nações da America latina, depois de tres seculos de producção, depois de ter visto sahir de seu sólo riquezas fantasticas - todo o assucar, café, ouro e diamantes do Brasil, todo o ouro e toda a prata da America hespanhola depois de ter produzido tanta riqueza, se acha tão pobre no dia da independencia como si dezenas de gerações de milhões de indios e negros não houvessem morrido de trabalhar, sobre um sólo fertilíssimo, semeado de minas preciosissimas. (...) Bastava que se houvesse fixado na America do Sul um decimo da riqueza arrancada ao trabalho do escravo, para que ella não precisasse andar hoje, pelo estrangeiro, a mendigar empréstimos que mais a empobrecem. Nada se empregou aqui, em cousa que signifique effectivamente riqueza: reservas economicas nenhumas; instrumentos de producção - escravos e açoites; regimen de trabalho - a ignorancia systematica, irreductivel... no dia da independencia, as novas nacionalidades se acharam sem industria, sem commercio nacional, sem capitães, sem riqueza, sem gente educada no trabalho livre, sem conhecimento do mundo. (BOMFIM, 1905, 140 et seq.) 
Posteriormente, em "Raízes do Brasil", livro publicado em 1936, de autoria de Sergio Buarque de Holanda, também caracterizaria o homem ibérico (o português e o espanhol) pela falta de aptidão no que concerne à organização, o desprezo pelo trabalho manual, entre outras coisas. Para Buarque de Holanda (2014), a cultura ibérica marcaria esses novos territórios por meio de estruturas sociais desajustadas, relações personalistas e também uma ausência de hierarquias organizadas. Portanto, tais características tornavam-se entraves para o desenvolvimento, uma vez que as relações personalistas levavam à busca desenfreada por prestígio e satisfação pessoal ${ }^{8}$. Buarque de Holanda também descreveu a capacidade de assimilação do português ao meio americano, e, aqui mais precisamente, isso se explicaria pelo espírito aventureiro do português, bem diferente do holandês que aqui não se adaptou.

A família rural foi uma categoria importante para Buarque de Holanda, e é por meio desse modelo familiar patriarcal tradicionalista que este autor inclusive irá entender o fazer política no Brasil. Entretanto, para compreender a significação que o autor dá à família rural, é necessário primeiro compreender a dicotomia estabelecida em

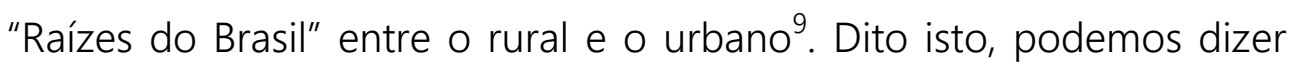
que a família rural descrita por Buarque de Holanda estava fundada na obediência ao patriarca. Tal modelo de organização familiar inundaria a vida política e o fazer política no Brasil, e, por fim, moldaria o homem cordial, constructo psicológico que corresponderia à repulsa dos brasileiros às relações impessoais, pois é movido por relações de simpatia e afeto. Neste sentido, o homem cordial ${ }^{10}$ é um tipo ideal que necessariamente não tem como traço a bondade; conceitualmente, não é disso que se trata, mas sim da busca por relações pessoais e afetivas nas mais variadas esferas sociais.

Em relação ao Estado brasileiro e suas estruturas relacionais arcaicas analisadas por Sergio Buarque de Holanda (2014) e Raymundo Faoro (1977) por meio da noção de Patrimonialismo, ambos sob a influência weberiana, Manoel Bomfim analisou por meio do seu conceito de Conservadorismo essencial. Tal conceito orientou Bomfim na descrição dos interesses pessoais como determinantes no funcionamento interno das instituições brasileiras, mas esse tipo de
${ }^{8} \mathrm{O}$ caráter personalista das relações sociais aqui estabelecidas impõe obstáculos para a construção de uma sociedade

verdadeiramente democrática. Contudo, as chaves explicativas deste continuísmo relacional que se demonstra preservado no seio da sociedade brasileira e em suas instituições ligam-se diretamente ao sentido que a colonização portuguesa teve em nosso território e a herança nos legada pelos portugueses.

9 Segundo Buarque de Holanda, havia um predomínio da fazenda em relação à cidade - em que a primeira estava intimamente ligada à nobreza e a suas atividades diárias, ao passo que a cidade era vista nesta configuração como uma extensão da fazenda, pois, era "usufruída" nos momentos especiais pelos ricos latifundiários de outrora. Destarte, o meio rural associava-se concomitantemente à matriz econômica nacional (a agricultura) e simultaneamente ao trabalho compulsório.

\footnotetext{
10 Este caráter na esfera política cria o problema da penetração patrimonialista, ou seja, a falta de distinção entre os domínios da esfera pública e da esfera privada - nesta perspectiva, ambas as esferas são fortemente marcadas por relações pessoais, de simpatia e afetividade.
} 
conservadorismo seria um elemento educacional aprendido nas relações que foram estabelecidas aqui com o colonizador europeu. Neste sentido, afirmava Bomfim:

As instituições sociaes eram reproducções grosseira e
viciada das instituições da peninsula: os feudos,
representados nas fazendas e dominios mineiros; a
servidão, na escravaria ignara, alvitada pelo tronco e o
calabrote. A religião é o fetichismo, a superstição bronca; a
familia é um pedaço de tribu, semi-feudal, semi-
patriarchal, degradada pela ociosidade sobre o trabalho do
negro, pervertida pelo espectaculo permanente dos
barbaros tratamentos e castigos, infligidos ao escravo.
(BOMFIM, 1905, p. 152)

Desta maneira, temos uma descrição processual igualmente importante, ainda que operada por conceitos distintos - e, além disso, temos também um retrato factual da perversidade cometida junto ao negro aqui escravizado, bem distante das relações romantizadas por Gilberto Freyre no que diz respeito à relação senhor e escravizado (FERNANDES, 2017). Pois em "Casa-Grande \& Senzala", livro publicado em 1933, a análise do autor pauta-se na família como uma categoria nuclear de explicação. Por um lado, o patriarca é o personagem central, já por outro lado, a mulher e o escravo são os personagens secundários, orbitando em torno do patriarca, e o universo em que a trama se desenrola em sua análise é o meio açucareiro agrárioindustrial (BASTOS, 2013).

Freyre (1981) apontou que no caso brasileiro tivemos uma especificidade importante, que foi o tipo de escravidão menos bruta e segregacionista do que as formas de escravidão das colônias espanholas e inglesas. Isso se deu pelo que o autor chamou de processo de miscibilidade, para compensar o déficit populacional português. Desta forma, desde os primeiros anos da colonização, o português teria se misturado com as mulheres nativas e mais tarde com as mulheres africanas. Não à toa, Florestan Fernandes (2017) afirmou que a forma com que Gilberto Freyre refletiu e descreveu as relações raciais no Brasil

(...) acabou traduzindo o problema da sociedade brasileira como uma equação linear, pela qual a solução dos problemas raciais brasileiros procederia do mestiçamento. 
Falando chulamente, passado e presente fluiriam em uma síntese: a solução viria da "pica", com fusão de portugueses e africanos - o mestiçamento desenvolveria a igualdade racial. O negro teria sido o elemento desagregador da família (e por conseguinte da sociedade) patriarcal. A miscigenação cumpriria, nesse sentido, a função de classifica-lo como mestiço em uma nova estrutura social. Antonio Candido é um especialista no estudo da família e pode nos dar uma lição sobre isso. Gilberto Freyre pinta um belo quadro idílico: ao desagregar a família patriarcal por dentro, o negro derrotou os costumes. A mulher escrava, seduzindo o senhor ou seu filho; o homem escravo, seduzindo as mulheres brancas ou suas filhas. Criaram-se, assim, grandes dilemas no plano das relações raciais e a miscigenação foi vista, em si mesma, como matriz de uma nova ordem racial. Ora, o Antonio Candido demonstrou muito bem, em seu estudo: a miscigenação se processava na periferia da família patriarcal, não em seu núcleo. Portanto, ela não transmitia posição social. Como dizia Frei Vicente de Salvador, o português trouxe para cá dois preconceitos: um, era o preconceito de não ter mácula de trabalho mecânico; o outro, era o preconceito de não ter mácula de sangue, mistura de sangue. Isso quer dizer que a miscigenação não contribuía para criar classificação e muito menos igualdade racial. Ela não promovia a ascensão do mulato e do negro escravo, liberto ou livre (FERNANDES, 2017, p.117-118).

Na visão romantizada de Freyre (1981), que pressupõe como agente propositivo das ações o negro, configura-se um eufemismo. Descrever a mulher negra escravizada como "sedutora" do senhor, uma vez que esta era uma vítima sistemática de estupro na vigência da ordem escravocrata. Gilberto Freyre, ao tentar demostrar certa relação consensual, acabava mais por romantizar a relação entre os donos dos escravizados e suas propriedades legais no período. Assim, nos parece que na tentativa de relativizar culturalmente para distanciar-se das visões correntes de grande parte de uma tradição intelectual anterior, Freyre não consegue se desvencilhar totalmente da defesa do senhor da casa-grande e, assim, acusa por uma suposta perversão sexual a mulher escravizada - isso sem refletir seriamente quais eram as possibilidades de se protegerem dessa violência impetrada pelos seus senhores e filhos.

Por fim, cabe ressaltar que a noção de laços de sangue como meio que propiciou o sucesso da empreitada portuguesa em solo 
americano e levou ao mestiçamento de parte significativa em termos quantitativos da população brasileira foi previamente assinalado por Manoel Bomfim em seu ensaio histórico-sociológico de 1905. Entretanto, Bomfim o mobilizou sem tentar relativizar violência alguma, ou mesmo transmitir para as vitimas a pró-atividade no processo, por um lado; já por outro lado, o mestiçamento que Bomfim descreveu era um fato objetivo dos laços de sangue, que não criava status ou ascensão social, por isso mesmo, não se configurava uma relação de harmonia.

Não obstante, Manoel Bomfim sustentava que a falta de observação leva as elites latino-americanas a desconsiderarem as condições materiais e históricas de formação destas jovens repúblicas, o que, no limite, se materializava em pressupostos incompatíveis com as reais necessidades destas nações. Isto porque não houve um rompimento efetivo com as iniquidades do passado; ao invés disso, há a atualização dos mesmos processos em outros moldes. Dizia o médico em relação à reforma que se acreditava fazer com o fim do regime escravocrata:

Decretou-se a libertação, e fôram-se todos, considerando a reforma como acabada; e si alguem ainda se occupou do caso - foi para pedir ou propor que se importassem braços baratos, que podessem substituir os antigos escravos, nada se alterando nos costumes e nos processos: chinezes ou italianos, que viessem occupar as antigas senzalas - um salario baixo, equivalente á alimentação e ao juro do preço do negro... tudo mais como dantes. Quanto a essa população das classes inferiores, antigos escravos, nacionais proletarios - quanto a estes: que sejam obrigados por lei a trabalhar; pedem-se leis sobre a vagabundagem, lei de locação de serviços, na convicção de que, no momento em que alguns decretos, substanciosos de artigos e paragraphos, vierem publicados, todos esses homens tornarão logo activos, adorando o trabalho, e dispostos a dar o seu labor ao fazendeiro ocioso e bruto, por um salario miseravel. (...) o fazendeiro, que viveu sempre parasita, já não quer somente braços baratos; reclama tambem quotas directas, em especie - auxílios á lavoura, compensação aos lucros cessantes... Hontem parasita do escravo, hoje parasita do Estado (...). (BOMFIM, 1905, p. 180 et seq) 
A citação acima revela muito da disparidade argumentativa deste médico em relação aos demais contemporâneos e quão similar eram seus pressupostos em relação a uma tradição intelectual posterior à sua (CANDIDO, 1990; RIBEIRO, 1993; IANNI, 2004). Outrossim, vale ressaltar que dentre os autores brasileiros, Manoel Bomfim foi o primeiro a apresentar como saída para fugir da ingerência europeia e norte-americana uma integração das nacionalidades latino-americanas (ALVES FILHO, 1979; GONTIJO, 2010; GIL, 2016), divergindo, assim, da proposição anterior à sua, estabelecida pelo tio-avô de Caio Prado Jr., estabelecida em "A Illusão Americana" (PRADO, 1895).

Destarte, a concepção bomfimniana mantém certa similaridade em alguns postulados de "Formação do Brasil Contemporâneo", escrito pelo intelectual paulistano, Caio Prado Junior e publicado em 1942. O objetivo deste trabalho foi compreender a formação social brasileira tomando como chave a transição entre o período colonial e a nação. A abordagem que Prado Jr (1972) empregou tentava pôr em xeque as abordagens correntes que eram idealizadas e pouco se detinham em torno do país real. Para tal empreitada, Prado Jr parte do método marxista de análise para tentar dar conta dos seus objetivos neste trabalho.

Sua questão central em "Formação do Brasil Contemporâneo" era demonstrar como a presença do passado colonial é preponderante para a compreensão de variadas dimensões do Brasil-nação. Por conta disso, segundo o autor, fazia-se necessária a investigação dos três séculos de organização colonial em que se fundaram os elementos centrais da nacionalidade brasileira para, a partir daí, tornar legíveis os processos e as dinâmicas do Brasil contemporâneo.

Na abordagem de Prado Jr (1972), a economia colonial era marcada pela seguinte dualidade: se por um lado havia uma concentração de atividades voltadas a grande exploração, por outro se particularizava pelo baixo nível tecnológico que se materializava numa total falta de dinamismo, cujos objetivos estavam subordinados a condicionantes internacionais. Contudo, como em muitas de suas alegações racistas ao longo do livro (SLENES, 2011), Prado Jr sustentava que o modelo irracional e pouco dinâmico do trabalho que se 
desenvolvia no período tinha vinculações diretas ao trabalho do escravizado africano descrito pelo autor como "semibárbaro"11 e, também, pelo regime de organização administrativo e político imposto por Portugal.

\section{Em Prado Jr (1972) a instituição escravidão possuía certa} centralidade para a interpretação da realidade brasileira (ainda que enviesada ${ }^{12}$, pois as persistências de elementos arcaicos numa dinâmica moderna possuem íntimas ligações com os contornos econômicos, políticos, sociais e até mesmo relacionais estabelecidos dentro da lógica operacional do passado. No fim, se Caio Prado Jr enxergava animosidade e selvageria nos costumes de negros e indígenas, o mesmo não é visível no texto inaugural de Manoel Bomfim, que em 1905 (37 anos antes da publicação do livro de Prado Jr.) mostrava com uma dose de ironia $^{13}$ o quão selvagem foram as práticas dos colonizadores, seja nas Américas, na África ou em outros pontos do globo terrestre; das riquezas que foram pilhadas aos povos que foram massacrados. No mais, após todo o exposto, tendemos a concordar com a assertiva do antropólogo Darcy Ribeiro (1993), que afirmou que só

(...) muitas gerações depois as interpretações magistrais de Manoel Bomfim entraram em curso, lidas todas em outros autores. Muito antes de Gilberto Freyre aprender isto em Nova lorque - como a sabedoria mais sábia da Universidade de Colúmbia - Manoel Bomfim dizia com toda clareza que as taras do crioléu não vinham da raça, mas da escravidão (...) Caio Prado ainda estava nascendo quando Manoel Bomfim nos falava com exatidão do caráter classista, intrinsicamente tirânico e espoliativo, do Estado brasileiro, por isso mesmo, justamente odiado ontem e hoje pelo povo. Também antes do que qualquer outro, Manoel Bomfim nos deu o diagnóstico do racismo como a técnica ideológica européia de dominação e escravização. O próprio Gilberto, quando retoma essas teses, trinta anos depois, o faz torpemente, encantado que estava com a bondade do senhor de engenho. Até o reconhecimento dos méritos do português como povo com grande capacidade de assimilação e de adaptação é assinalado por Manoel Bomfim, que o faz sem cair nos tropicalismos coloniais de Gilberto. (...) Multiplicaram-se, depois de Gilberto, os autores que se acercavam da visão de Manoel Bomfim, tais como Arthur Ramos, Josué de Castro, Sérgio Buarque, Caio Prado. Nenhum deles, porém, o leu. (RIBEIRO, 1993, p. 15)
11 Cf. "Se em Freyre a explicação sociológica retirava do negro o fardo da "raça", no trabalho de Prado ela Ihe atribuía outro peso: o de uma profunda deformação de caráter e cultura sob o escravismo, com implicações para sua história subsequente. $\mathrm{O}$ quadro era atenuado apenas pelo fato de que o "desregramento" moral, segundo Prado, atingia por razões estruturais a massa da população livre, marginalizada pelo sistema escravista, e até contaminava os próprios senhores. Ironicamente (...) "a promiscuidade com escravos, e escravos do mais baixo teor moral", entre outras características da vida senhorial, tornara a casagrande "uma escola de vício e desregramento" para a criança branca." (SLENES, 2011, p. 37-38)

13 Em relação aos povos indígenas e os negros aqui escravizados, Caio Prado Jr sustentava que se tratavam de "povos de nível cultural ínfimo (...) simples máquina de trabalho bruto e inconsciente (...) povos bárbaros e semibárbaros (...) pretos boçais e índios apáticos" (PRADO JR, 1972, p. 272, 277).

${ }^{31}$ Cf. BOMFIM, 1905, páginas 276-277. 
O que Darcy Ribeiro nos informa por meio de sua argumentação é o pioneirismo analítico de Manoel Bomfim frente não só aos seus contemporâneos, mas também à possibilidade posterior de leitura dos pressupostos bomfimnianos em importantes intelectuais brasileiros, sobretudo nos intelectuais da chamada geração de 30 . Todavia, é importante salientar que a não referência a Bomfim nestes trabalhos posteriores pode ser compreendidos pela lógica do silêncio e da ignorância (no sentido de ignorar algo). Logo, devemos ter em mente que cada época apresenta limites em seu vocabulário normativo, o que determina em última análise como determinadas questões serão identificadas e discutidas. Da mesma forma o silêncio torna-se aparato consciente, uma vez que os autores não se limitam a concordarem ou mesmo explicitamente atacarem os postulados uns dos outros. Portanto, o silêncio neste caso opera como meio de ignorar o outro de forma polêmica, sendo aqui o silêncio observável com certo grau de veemência (SKINNER, 1996).

Para o jornalista, acadêmico ${ }^{14}$ e intelectual maranhense Humberto de Campos (1886 - 1934), em seu texto intitulado "Manuel

${ }^{14}$ Membro da Academia Brasileira de Letras (ABL). Bomfim", redigido dois dias após a morte do médico sergipano, destaca a fundação de uma narrativa nova, cuja intelectualidade contemporânea e posterior poderiam se furtar por meio dos caminhos abertos por Bomfim. Segundo Humberto de Campos:

\footnotetext{
Manuel Bonfim, foi, na verdade, uma das mais vigorosas organizações mentais que o Brasil tem produzido. Possuía uma noção segura e original de todos os nossos problemas, fossem políticos, sociais, ou literários, com os quais formava panoramas novos no mundo do conhecimento. Produzia muito, e vendia por grosso. Cada um dos seus livros é um vasto armazém de idéias, capaz de abastecer uma academia ou uma geração. Daí a forma compacta, a densidade e o volume de cada um deles. Não editava artigos nem folhetos. Na floresta das idéias não colhia flores nem cortava arbustos: derrubava madeiros, atacava cedros e jequitibás, que lançava, inteiros, à correnteza, para que outros no futuro os desbastem, aproveitando-os para construções leves e elegantes. Era um selvagem magnífico, de músculos poderosos, que trabalhava numa selva solitária, usando, ainda, como se observa no seu estilo, rude machado de pedra. (...) Isolado na sua geração, não só pela originalidade do temperamento como pela orientação da cultura, não
} 
desfrutou a popularidade amável dos companheiros. (CAMPOS, 1982, p. 34)

Observamos que as características descritas por Humberto de Campos, Darcy Ribeiro e Antonio Candido nos subsidiam na afirmação de que Bomfim foi algo mais que o autor de seus próprios livros. Pois a forma pela qual Manoel Bomfim leu os processos sociais do passado e produziu suas narrativas-textuais abriu inúmeras possibilidades posteriores de tomada interpretativa do Brasil, utilizando simbioticamente o passado colonial e a escravidão como chaves explicativas para a compreensão do Brasil do presente. Diametralmente oposta ao pensamento intelectual de seus antecessores, contemporâneos e até alguns intelectuais posteriores, a título de ilustração, destacamos por exemplo: Sylvio Romero (1888a, 1888b), Nina Rodrigues (1932, 1936); João Baptista de Lacerda (1912); Renato Kehl (1929); Oliveira Vianna (1934, 1942), entre outros. Como afirma Mitsuko Aparecida Makino Antunes:

Bomfim, num esforço de análise sobre a sociedade brasileira, adotou uma perspectiva em que procurava demonstrar que os problemas enfrentados pelo país deveriam ser buscados em suas raízes históricas, particularmente na sua formação colonial, baseada na exploração imposta rudemente pela metrópole. Em sua análise, considera que uma das mais nefastas consequências da exploração sobre a colônia incidiu sobre a cultura e aponta nessa direção a superação dos problemas nacionais; para o autor, um dos principais determinantes do atraso do país era a ignorância historicamente imposta pelas classes dominantes ao povo brasileiro, estando na difusão da educação a solução para os problemas, não apenas como remédio para o atraso econômico mas, principalmente, como meio de conquista da liberdade pelo povo brasileiro, caminhando de fato para a democratização da sociedade. (...) Paralelamente, deve-se acrescentar que, para alguns intelectuais, o atraso do país devia-se à diversidade de raças, sobretudo à presença da raça negra, considerada inferior, porque, segundo eles ela trazia em si os germes da apatia, da indolência e da preguiça, além de sua propensão à degeneração psíquica e, assim sendo, constituía-se como entrave ao progresso. Diametralmente oposta era a concepção de Bomfim, para quem essas idéias eram equivocadas e, ao contrário de contribuírem para a solução dos problemas do país, tendiam a perpetuá-los. (ANTUNES, 1998, p. 69-70) 
Demonstramos a importância das teses de Manoel Bomfim que formam o grosso do conteúdo de "A América latina: males de origem" (1905) - teses que mais tarde seriam refinadas e também reformuladas em sua trilogia: "O Brasil na América" (1929), "O Brasil na História" (1931) e o "Brasil Nação" (1931). Com os devidos cuidados tomados no que concerne às limitações temporais do autor, Bomfim apresentou em 1905, para o Brasil, pressupostos que representaram a fundação de um abismo narrativo-textual entre o pensamento hegemônico da intelectualidade brasileira de seu contexto. Posteriormente, suas teses entrariam novamente em circulação em outros intelectuais brasileiros.

Todavia a importância dos postulados formulados por Manoel Bomfim numa tradição ensaística posterior à sua pode ser explicado de forma coerente por meio da noção de sequências cognitivas (BOTELHO, 2007; 2019), isso porque tal noção nos permite analisar os principais elementos, seja em termos de continuidades ou descontinuidades, que ligam os pressupostos Bomfimnianos às produções posteriores. Então, é neste sentido que "A América Latina: males de origem" (1905), tomando a sugestão de André Botelho, se "mostrou capaz de interpelar, no plano cognitivo, diferentes trabalhos posteriores, não obstante muitos deles divergirem radicalmente do seu sentido político original" (BOTELHO, 2007, p.50).

Portanto, há uma interpelação que é capaz de ser identificada em dois planos distintos: o primeiro, teórico-metodológico e o segundo, substantivo (BOTELHO, 2007). O primeiro estando intimamente ligada à análise social estabelecida pelo autor no seu tempo e formalizando certas linhas interpretativas para determinados temas e problemas, pelos quais se encontrariam os fundamentos das dinâmicas histórico-sociais e institucionais; no caso de Bomfim, tal percepção exigiu do autor um movimento de ruptura com as abordagens pseudocientíficas europeias e o esforço de construção de mecanismos objetivos para a compreensão brasileira (e latinoamericana). Já o segundo vincula-se diretamente ao fato de suas teses devido às persistências de diversos elementos do passado, conhecer distintos desdobramentos na produção ensaística e científica posteriormente (BOTELHO, 2007; 2019). Em suma, por tudo isso, entendemos a relevância de posicionar Manoel Bomfim como peça 
importante na composição dos cânones do Pensamento Social Brasileiro.

\section{CONSIDERAÇÕES FINAIS}

Manoel Bomfim foi um intelectual ligado ao seu tempo e estava preocupado com as questões da mesma, ainda que uma série de outras questões refletidas pelo autor possam ser observadas nos dias de hoje. Em "A América Latina: males de origem", as narrativas-textuais foram organizadas e refletidas por outra chave explicativa, em que a relevância dos processos históricos singulares na constituição destas novas nacionalidades latino-americanas seria substancial para a compreensão dos problemas de nossa formação político-estrutural. Portanto, a "América Latina" de Bomfim, foi o primeiro estudo de Psicologia Social, História e Sociologia que, de forma dissonante, se contrapôs às respostas ancoradas nas teorias racistas em voga no período, alocando o problema em outra ordem, o que, por conseguinte, tornou legíveis os verdadeiros problemas encarados pela América do Sul e a fração majoritária de suas populações.

Na tradição do Pensamento Social Brasileiro, é possível ler M. Bomfim em outros autores de relevância para o campo, pois a noção de sequências cognitivas representa a "sobrevivência" de certos postulados em variadas produções intelectuais - ensaísticas ou científicas posteriores às suas, passíveis de interpelação num plano cognitivo. Dito isto, as inquietações que nos levaram a estas reflexões foram motivadas pelas maneiras díspares de serem tratados determinados autores em detrimento e/ou oposição a outros, em alguma medida, parecendo que uns são os fundadores do pensar sociologicamente em solo brasileiro em oposição aos autores "anacrônicos" do passado.

Entendemos que os cânones responsáveis pelas inovações no modo de pensar o Brasil que nos são apresentados nos cursos de Ciências Sociais no país são construções arbitrárias que desconsideram implicitamente o que foi produzido antes. Nosso objetivo aqui não foi questionar a geração de 30 e sua relevância para as ciências humanas e sociais, tampouco supor que nossa reflexão seja capaz de ter um 
efeito de reconstrução deste cânone, por isso no título do artigo apresentamos a ideia de "repensar". Ora, o que tentamos estabelecer aqui foi uma reflexão, trazendo para o debate um autor que levantou teses próximas dos intelectuais da geração de 30 quase três décadas antes. Daí a relevância do indicativo tanto de Darcy Ribeiro (1993), quanto de Antonio Candido (1990) em relação ao modo de interpretar o Brasil estabelecido pelo médico de formação, professor por vocação, sociólogo, historiador, pedagogo e antropólogo por aclamação, Manoel José do Bomfim (1868-1932).

\section{REFERÊNCIAS BIBLIOGRÁFICAS}

AGUIAR, Ronaldo Conde. O rebelde esquecido: tempo, vida e obra de Manoel Bomfim. Rio de Janeiro: ANPOCS/Topbooks, 2000.

ALVES FILHO, Aluízio. Pensamento Social no Brasil - Manoel Bomfim um ensaísta esquecido. Rio de Janeiro: Achiamê, 1979.

ANTUNES, Mitsuko Aparecida Makino. A psicologia no Brasil: leitura histórica sobre sua constituição. São Paulo: Unimarco/Educ, 1998.

BASTOS, Élide Rugai. Gilberto Freyre e Florestan Fernandes: um debate sobre a democracia racial. In: MOTTA, Roberto; FERNANDES, Marcionila (org). Gilberto Freyre: religião, trópicos e outras aproximações. Rio de Janeiro: Fundação Miguel de Cervantes, 2013, pp. 261-278.

BASTOS, Maria Helena Camara. Pro pátria laboremus: Joaquim José de Menezes Vieira (1848 - 1897). Bragança Paulista/SP: Ed. Universidade de São Francisco, 2002.

BENDIX, Reinhard. Construção nacional e cidadania: estudos de nossa ordem social em mudança. São Paulo: Edusp, 1996.

BOMFIM, Manoel. A America Latina: males de origem. Paris: H. Garnier, 1905.

O Brazil na America: caracterização da formação

brazileira. Rio de Janeiro: Francisco Alves, 1929.

O Brazil na Historia: deturpação das tradições degradação politica. Rio de Janeiro: Francisco Alves, 1931. 
- O Brazil Nação: realidade da soberania brazileira - Tomo I. Rio de Janeiro: Francisco Alves, 1931.

O Brazil Nação: realidade da soberania brazileira - Tomo II. Rio de Janeiro: Francisco Alves, 1931.

Cultura e educação do povo brasileiro: pela diffusão da instruç̧ão primaria. Rio de Janeiro: Pongetti, 1931.

BOTELHO, André. Seqüências de uma Sociologia Política Brasiliera. Dados - Revista de Ciências Sociais, Rio de Janeiro, vol.50, n¹, pp.4982, 2007.

O Retorno da Sociedade: Política e interpretações do Brasil. Petrólolis-RJ: Vozes, 2019.

BOURDIEU, Pierre; CHAMBOREDON, Jean-Claude; PASSERON, JeanClaude. O ofício de sociólogo: metodologia da pesquisa em Sociologia. 5. ed. Petrópolis/RJ: Vozes, 2004.

CAMPOS, Humberto de. Obras escolhidas. Vol. 8. Sepultando meus mortos. Rio de Janeiro: W. M. Jackson, 1982.

CANDIDO, Antonio. Radicalismos. Estudos Avançados, São Paulo, 4(8), 1990, pp. 5-18.

ELIAS, Norbert. O Processo Civilizador volume l: uma história dos costumes. 2. ed. Rio de Janeiro: Zahar, 1994

FAORO, Raymundo. Os donos do poder - formação do patronato político brasileiro. 4. ed. Porto Alegre/RS: Globo, 1977.

FERNANDES, Florestan. Significado do Protesto Negro. São Paulo: Expressão Popular, 2017.

FREYRE, Gilberto. Casa-Grande \& Senzala: a formação da família brasileira sob o regime da economia patriarcal. 21. ed. Rio de Janeiro/Brasília: José Olympio, 1981.

GIL, Mónica Albizúrez. Modernidades extremas Textos y prácticas literarias en América Latina Francisco Bilbao, Manuel Gonzáles Prada, Manuel Ugarte y Manoel Bomfim. Madrid/ Frankfurt am Main: Iberoamericana/ Vervuerte, 2016. 
GONTIJO, Rebeca. Manoel Bomfim. Recife: Fundação Joaquim Nabuco/ Massangana, 2010.

HOLANDA, Sergio Buarque de. Raízes do Brasil. 26. ed. São Paulo: Companhia das Letras, 2014.

IANNI, Octavio. Pensamento Social no Brasil. Bauru-SP: EDUSC, 2004.

KEHL, Renato. Lições de eugenia. Rio de Janeiro: Francisco Alves, 1929.

LACERDA, João Baptista de. O Congresso Universal das Raças reunido em Londres (1911): apreciação e commentarios. Rio de Janeiro: Museu Nacional, 1912.

MEDEIROS, Mauricio Campos de. Manuel Bomfim e a Psychologia. In: MEDEIROS, Mauricio Campos de. Ideas, Homens e Factos. Rio de Janeiro: Calvino Filho, 1935, pp.157-170.

OLIVEIRA, Lucia Lippi. Manuel Bomfim: autor desconhecido ou fora do tempo? Revista Sociologia e Antropologia. V. 05.03. Rio de Janeiro, dezembro. p. 771-797, 2015.

PRADO, Eduardo. A Illusão Americana. 2. ed. Paris: Armand Colin et cie, Editeurs, 1895.

PRADO JUNIOR, Caio. Formação do Brasil contemporâneo: colônia. 12. ed. São Paulo: Brasiliense, 1972.

RIBEIRO, Darcy. Manoel Bomfim, antropólogo. In: Bomfim, Manoel. América Latina: males de origem. 3. ed. Rio de Janeiro: Topbooks, 1993.

RODRIGUES, Nina. Os africanos no Brasil. São Paulo: Companhia Editora Nacional, 1932.

As raças humanas e a responsabilidade penal no Brasil.

3. ed. São Paulo: Companhia Editora Nacional, 1938.

ROMERO, Sylvio. A America Latina (Analyse do livro de igual título do Dr. M. Bomfim). Porto: Chardron, 1906.

Historia da litteratura brasileira - tomo primeiro (15001830). Rio de Janeiro: B. L. Garnier, 1888a.

Historia da litteratura brasileira - tomo segundo (1830-

1877). Rio de Janeiro: B. L. Garnier, 1888b. 
SANTOS, José Geraldo dos. Manoel Bomfim: racialismo, mestiçagem e índios. Dissertação (mestrado em História). Universidade Salgado de Oliveira. Programa de Pós-graduação em História; Niterói, 2017a, 220 fls.

SANTOS, Patrick Silva. Manoel Bomfim: voz dissonante do Pensamento Social Brasileiro. Dissertação (mestrado em Sociologia). Universidade Federal Fluminense, Instituto de Ciências Humanas e Filosofia. Programa de Pós-graduação em Sociologia; Niterói, 2017b, 192 fls.

SCHWARCZ, Lilia M. O Espetáculo das Raças: cientistas, instituições e questão racial no Brasil 1870 - 1930. São Paulo: Companhia das letras, 1993.

SKINNER, Quentin. As fundações do pensamento político moderno. São Paulo: Companhia das Letras, 1996.

SLENES, Robert W. Na senzala, uma flor - Esperanças e recordações da família escrava: Brasil sudeste, século XIX. 2. ed. Campinas/SP: Unicamp, 2011.

SUSSEKIND, Flora; VENTURA, Roberto. História e dependência cultura e sociedade em Manoel Bomfim. São Paulo: Moderna, 1984.

VIANNA, Oliveira. Raça e Assimilação. 2. ed. São Paulo: Companhia editora nacional, 1934.

Pequenos estudos de psychologia social. 3. ed. São Paulo: Companhia editora nacional, 1942.

WEBER, Max. Economia e Sociedade: fundamentos da sociologia compreensiva. Brasília: UnB, 1999. 